Article

\title{
Beyond Legal Status: Exploring Dimensions of Belonging among Forced Migrants in Istanbul and Vienna
}

\author{
Susan Beth Rottmann ${ }^{1, *}$, Ivan Josipovic ${ }^{2}$ and Ursula Reeger ${ }^{2}$ \\ ${ }^{1}$ Faculty of Social Sciences, Özyeğin University, 34794 Istanbul, Turkey; E-Mail: susan.rottmann@ozyegin.edu.tr \\ 2 Institute for Urban and Regional Research, Austrian Academy of Sciences, 1010 Vienna, Austria; \\ E-Mails: ivan.josipovic@oeaw.ac.at (I.J.), ursula.reeger@oeaw.ac.at (U.R.) \\ * Corresponding author
}

Submitted: 1 August 2019 | Accepted: 9 December 2019 | Published: 25 March 2020

\begin{abstract}
Migrants with precarious legal statuses experience significant structural exclusion from their host nations but may still feel partial belonging. This article explores two dimensions potentially relevant for this group's sense of belonging: city-level opportunity structures and public political discourses. Specifically, we examine perceptions of belonging among forced migrants with similarly precarious legal statuses located in Istanbul and Vienna. Drawing from semi-structured interviews, we argue that opportunity structures in the cities provide a minimal sense of social normalness within a period of life otherwise considered anomalous or exceptional. Any articulations of belonging in this context however remain inherently tied to the conditions of legal limbo at the national level. With regard to public political discourses, migrants display a strong awareness of the role of religion within national debates on culture and integration. In a context where religion is discussed as a mediator of belonging, we found explicit affirmations of such discourses, whereas in a context where religion is discussed as a marker of difference, we found implicit compliance, despite feelings of alienation. Overall, this article shows the importance of differentiating belonging, and of cross-regional comparisons for highlighting the diverse roles of cities and public political discourses in facilitating integration.
\end{abstract}

\section{Keywords}

asylum; belonging; city; culture; integration; Istanbul; legal limbo; Vienna

Issue

This article is part of the issue "Boundary Spanning and Reconstitution: Migration, Community and Belonging" edited by Anya Ahmed (University of Salford, UK).

(C) 2020 by the authors; licensee Cogitatio (Lisbon, Portugal). This article is licensed under a Creative Commons Attribution 4.0 International License (CC BY).

\section{Introduction}

The political crisis of migration governance in 2015 spurred new public debates on immigrant integration in host societies within the EU and beyond. Policymaking classically entails a discursive construction of policy recipients (Pierce et al., 2014), and in the context of integration, political debates oftentimes evolve around immigrants' willingness or capability to belong to a nationally defined society. In this vein, research has long been focused on the way in which powerful actors construct immigrants as part of or excluded from the society (e.g., van Leeuwen \& Wodak, 1999; Wright \& Bloemraad, 2012;
Yuval-Davis, 2006). However, scholars are increasingly paying attention to a subjective dimension of integration, namely, the way in which newly arrived immigrants experience belonging - a sense of identification and attachment to society (Antonsich, 2010; Crowley, 1999; Howes \& Hammett, 2016; Simonsen, 2016).

The topic of belonging is far from trivial. At the individual level, a sense of belonging can create meaning and a feeling of safety (Lambert et al., 2013); at the societal level, it contributes to social cohesion (Schiefer \& Noll, 2017). In this article, we take up the topic by examining perceptions of belonging among forced migrants located in Vienna and Istanbul and living in legal limbo. We re- 
fer to the social group of our study as "forced migrants" because of their position vis a vis state categories of migration governance. This umbrella term encompasses people requiring asylum or another form of protection abroad and holding a variety of related legal statuses. It does not preclude the possibility that their process of migrating is at least partially voluntary or that receiving states may not formally recognize them as refugees (cf. Erdal \& Oeppen, 2018).

In this article, we are first interested in whether and how the level of cities as a subnational entity may contribute to feelings of belonging, providing integrational structures in an exclusionary national context. The two cities were chosen because they are both immigration cities offering opportunity structures in countries that received relatively high numbers of asylum seekers in recent years. The choice of these cities also allows for a novel comparison between European and non-European contexts. Second, we seek to address the level of public political discourse on culture and integration, which differs considerably between Austria and Turkey. National debates on culture and integration can be viewed as important venues of negotiation regarding who belongs to a society and based on which features.

Thus, we study perceptions of belonging by analyzing qualitative interviews with forced migrants who arrived in Austria and Turkey between 2011 and 2017, paying particular attention to our interlocutors' discussions of city specific opportunity structures and public political discourses on forced migrants. The central question that we address in this article is: How do persons with a precarious legal status experience belonging in specific urban contexts? Drawing together results from two different cities enables us to explore the practical and cognitive-cultural role of cities and public political discourses in integration processes.

In the following section, we introduce the concept of belonging, explain how it is tied to the structural conditions of forced migrants, particularly in the context of cities, and discuss how it is related to public political discourses on integration and culture. In the third section, we present our two cases. First, we discuss the national legal and discursive settings that forced migrants face, then we look at city-specific integration policies for this group. Afterwards, in section four, we elaborate on our data and methodology. In section five, we present the central findings deriving from an analysis of semistructured interviews with asylum seekers and beneficiaries of protection status in Vienna and Istanbul. The final section of the article sums up the major conclusions about the role of cities and public political discourses for migrants' perceptions of belonging.

\section{Theoretical Framework: The Concept of Belonging}

The concept of belonging addresses a person's identification and feelings of attachment to a community (Kannabiran, Vieten, \& Yuval-Davis, 2006; Simonsen,
2018). In our context, the focus is on forced migrants located within communities at the geo-political level of host-states and cities. Considering this nested situatedness, we seek to understand how persons who are nationally not granted full legal inclusion experience belonging. Thereby, we specifically take into account the role of the urban sub-spaces and public political discourses.

Belonging is an important component of immigrant integration. Integration is a concept that is widely used by policy makers, but it is a contested term for migration scholars who do not agree about its definition or measurement (Castles, de Haas, \& Miller, 2013). One primary critique of integration research is that it is overly focused on functional indicators and that scholarship does not sufficiently take migrant points of view into account. Increasingly, researchers are pointing to the importance of affective and subjective measures of integration, including social bridges, bonds and links (Ager \& Strang, 2008), as well as the cultural and religious dimensions of belonging (Garcés-Mascareñas \& Penninx, 2016).

Thus, the question of belonging is inherently tied to established social boundaries and their permeability in relation to newcomers. Specifically, boundaries might be related to being part of a territory, entering formal institutional settings or joining a symbolic community. Building on Max Weber, Andrew Geddes (2005, p. 789) argues that a political community is constituted by the confluence of three types of boundaries: territorial, organizational and conceptual. Accordingly, belonging is mediated (in chronological order) through a mid-to longterm presence within a legally demarcated space, a formally organized status of residence and access to major institutions, and self-identification or ascription processes in relation to collectively shared concepts of "us" and "them."

With regards to the first two categories (territorial and organizational belonging), forced migrants entering host countries like Turkey and Austria via the asylum system typically have overcome territorial boundaries, but they do not immediately receive long-term residence status and associated rights with regard to labour market participation, social welfare, or education. This condition is often referred to as legal limbo. Goldring and Landolt (2011, p. 327) describe limbo as "precarity" resulting from "complex institutional and geographic pathways" that force migrants into insecure legal statuses. Being in limbo may mean uncertainty and anxiety about the future and limited economic and social access to the host society (Robertson \& Runganaikaloo, 2014; Yijala \& Nyman, 2017). The longer that migrants have an unsecured status, the more frustrated and less interested in integration they may become. Against this background of limited organizational belonging within the nation-state, it seems worth looking at two other dimensions that might play a crucial role in mediating belonging, namely opportunity structures at the level of cities as organizational boundaries at the sub-national level and pub- 
lic political discourses on "us" and "them" as conceptual boundaries.

\subsection{Belonging Mediated by City Level Opportunity Structures}

Similar to debates on integration, questions of belonging are usually discussed in the context of national politics (e.g., Simonsen, 2018). The nation-state as an "imagined community" (Anderson, 1991) certainly retains its importance in a globalized world, especially as a guarantor of "the right to have rights," to put it into the terms of Hannah Arendt. However, as literature on civic stratification has shown, the inclusion of newcomers, especially asylum seekers, is always partial and conditional (Atac \& Rosenberger, 2013; Morris, 2003). Thus, for persons in legal limbo, who are furthermore often framed as unwanted or non-belonging in political discourses, nonnational opportunity structures are particularly relevant.

Cities per se display distinct socio-economic and socio-cultural conditions, which may be of relevance to immigrants given their specific formal and informal labour market opportunities as well as the increased possibilities to engage in interethnic networks that they offer. This can be referred to as indirect opportunity structures. However, it has also been shown that cities often lead national levels in terms of developing direct opportunity structures in the form of integration policies (Bauder \& Gonzalez, 2018; Penninx, 2009). In order to explain why some cities are more open to absorbing newcomers, scholars have pointed to favourable political conditions (de Graauw \& Vermeulen, 2016) and the ultimate necessity to deal with ethnic diversity that they face (Hickman, Mai, \& Crowley, 2012). Some even argue that cities are "urban imagined communities" (Callen, 2004) coexisting with the nation, due to their clear limitedness, their community building efforts, and their constant boosting of quality of life. Thus, cities might offer additional resources, structures and discourses that work as supplementary or compensatory sites of belonging for specific migrant groups.

\subsection{Belonging Mediated by Public Political Discourses on Integration and Culture}

Conceptual boundaries are frequently negotiated in terms of discourses on "us" and "them," which are often reflected in debates on culture and integration. Politicians and commentators may set out the criteria of cultural membership in terms of language mastery or other formal criteria, but more often they make recourse to more abstract notions of values, respect and national loyalty. Scholars have shown that such debates about culture and integration are very important for determining migrants' sense of belonging as they constrain possible narratives, reinforce inequalities (Cederberg, 2013) and can damage political trust and faith in democratic systems (Simonsen, 2019). These discourses may even be more important than legal policies for determining subjective belonging (Simonsen, 2019) and thus are worth examining in detail.

In ethnically diverse societies, integration issues are often brought up in connection to religion, and in Western European cases like Austria, Islam in particular (Permoser \& Rosenberger, 2012). Prior research has examined Muslim integration in several European countries (cf. Statham \& Tillie, 2016), compared immigrant integration in Europe and North America (Chambers, Evans, Messina, \& Williamson, 2017; Foner \& Alba, 2008) or Christian and Muslim integration in the Middle East (Chatty, 2010). There are, however, no comparative studies analysing the role of integration discourses on religion for perceptions of belonging, despite the noted significance of these discourses. Kassaye, Ashur, and van Heelsum (2016) for example point out how discourses on Muslims in Western European countries are dominated by an emphasis on cultural and religious difference, which often constructs the presence of Muslim migrants as a threat. In a study of the effects of media discourses on belonging among Somalis in the Netherlands, Kassaye et al. (2016) found that news about Muslims in the media are perceived as negative and excluding. The effect on belonging varies considerably, causing some Dutch Somalis to discount the importance of media coverage, some to deemphasize their Muslim background and some to display a strong attachment to the "Muslim community" as a reaction to excluding media discourses.

\section{The Two Cases: Istanbul and Vienna in Their National Contexts}

\subsection{National Level: Legal Conditions and Public Political Discourses in Turkey and Austria}

In both Turkey and Austria, we focus on forced migrants in legal limbo. In Turkey, the vast majority of forced migrants are Syrians (3.6 million total), but the country is also home to around 115,000 migrants from nine other countries, with Iraq and Afghanistan representing the second and third largest groups respectively (AIDA, 2018) Legally, most Syrians have Temporary Protection Status, which they may hold for an unspecified length of time and which comes with access to services (health, education, and the limited ability to obtain a work permit), but no access to citizenship or political rights. Non-Syrian asylum seekers have Conditional Refugee Status in Turkey (unless they are Europeans), which is similarly limited in terms of rights. Both groups lack freedom of movement between cities. All non-European asylum seekers in Turkey are excluded from becoming refugees because Turkey retains a geographic reservation to the United Nations 1951 Convention on the Status of Refugees and its 1967 protocol, restricting the definition of "refugee" to those forced to leave Europe. Forced migrants may be considered to be in limbo in Turkey because they lack any guarantee that they may remain. 
Due to their large numbers, Syrians are often the focus of policy objectives and media treatment. Increasingly, the political discourse is turning to the need for Syrians to return to Syria as soon as possible, which worsens their sense of instability. This group has often been described by policy makers as "guests" or "religious brothers," and culture is not seen as a significant integration issue in Turkey on either national or municipal levels. In addition to a shared religion (Sunni Islam), Syrians and Turks have a shared history dating back to the Ottoman Empire (Chatty, 2017; Kaya, 2016). In Istanbul, integration is not designed around ideas of cultural adjustment and change, but rather focuses on functional integration issues, such as education and labour market access (Coşkun \& Yılmaz Uçar, 2018; Erdoğan, 2017). In contrast to the discourse of religious brotherhood promulgated by leaders, newspapers and social media are increasingly taking a more negative view of Syrian migrants as a strain on Turkey's economy or involved in crime (Efe, 2018). Nevertheless, even in these reports, culture is usually not seen as an important factor for Syrians' non-belonging. Thus, not surprisingly, culture is not a focus of integration programming in Turkey or Istanbul.

According to the online database Statistics Austria, in Austria, 208,000 persons filed an asylum application between 2011 and 2016. The most important countries of origin of these forced migrants are Afghanistan $(52,600$ persons, $25 \%$ of asylum applicants) and Syria (44,400 persons, $21 \%$ of asylum applicants). Forced migrants have different levels of legal statuses with varying rights and obligations: Asylum applicants receive basic welfare support including health care. They have de facto no access to the labour market except for apprenticeships and charitable work and are required to live in the federal province where they receive basic welfare support. Once a positive decision on the asylum application has been made, beneficiaries of asylum or subsidiary protection may access the labour market and can choose where they want to reside. However, an element of uncertainty has been implemented in 2016 as even decisions on asylum can be revisited after three years. For persons with the title "subsidiary protection" this time span is even shorter (one year). Otherwise they are also allowed to work and to choose their place of residence. None of these statuses include direct access to citizenship or political rights and all of them include a limbo componentfrom very strong in the case of asylum seekers to weaker in the case of beneficiaries.

Immigrant integration has become a highly debated topic in Austria over the past few decades. At the national level, civic integration policies were particularly pushed during the early 2010s, obliging certain third country nationals and beneficiaries of international protection to take part in language and citizenship courses. A meritocratic paradigm (Gruber, Mattes, \& Stadlmair, 2016) followed the logic whereby integration is considered an end-result of individual efforts. Asylum seekers, however, generally remain excluded from national inte- gration policies. In this context, the dominant public narrative problematizes integration as something that immigrants lack (Permoser \& Rosenberger, 2012). Tellingly, the frame "unwillingness to integrate," once a rhetorical device of right wing populists, has moved to the political centre in recent years (Wodak, 2015). Furthermore, the arrival of people from Syria and Afghanistan in particular since 2015, has spurred public debates on culture and integration. Especially conservative and right wing political actors discussed values and religion, in particular Islam as major markers of difference. In this regard, Mattes (2017) points out how the category of "Muslim" is a racialized one in Austrian integration discourses in the sense that it is used to produce in- and outsider groups specifying the "truly" European population (Mattes, 2017, p. 101).

\subsection{City Level: Population Structure and Integration Paradigms in Istanbul and Vienna}

Istanbul and Vienna can both be called immigration cities, and each is also home to the highest numbers of forced migrants in their countries. Istanbul is the city with the highest foreign national population in Turkey and has the highest rate of immigration (166,044 people arriving in 2017; TurkStat, 2018). In Istanbul, most forced migrants are Syrians (558,437 total); they constitute $3.7 \%$ of the city's total population (Directorate General of Migration Management, 2019). Vienna is a destination for internal as well as international migrants. According to Statistics Austria, $40 \%$ of Vienna's population were born in another country and/or held a foreign citizenship at the beginning of 2018. Among these migrants, $40 \%$ come from EU/EFTA countries and $60 \%$ from third countries. Around the year 2015, Vienna also received forced migrants, most notably from Syria, Afghanistan and Iraq $(40,998$ total); they make up $2.2 \%$ of the city's total population. Despite representing a small percentage of the total population, these migrants receive outsized attention in the mainstream media in both countries making it essential to understand more about their feelings of belonging and how to strengthen social cohesion.

There is no coordinated integration policy either on national or local levels in Turkey. Officially, municipalities are barred from serving non-citizens (Erdoğan, 2017). However, some Istanbul municipalities, such as the Sultanbeyli and Sisli Municipalities, have taken leads in fostering integration by setting up affiliated associations. They are providing or supporting the provision of vocational training and job placement services, healthcare, psychological services, and social and economic aid (Coşkun \& Yılmaz Uçar, 2018).

Austria for a long time lacked a comprehensive national integration policy. However, Vienna has a long history of making integration policy, and started more than two decades earlier than the national level. As early as 2015 , the city implemented a program called "Integration from Day 1," which provides integration measures for asylum seekers and refugees. It also has 
a stand-alone Municipal Department for Integration and Diversity (MA 17) that has defined its own integration concept for Vienna, which is rather inclusive in nature, contrary to the agenda of the federal level. Furthermore, the City of Vienna offers non-mandatory workshops on a large number of relevant issues, such as education, employment, housing, and even conviviality.

\section{Data and Methodology}

In order to analyse perceptions of belonging among persons with precarious legal statuses in Istanbul and Vienna, we draw on fieldwork carried out under the HORIZON 2020 project "RESPOND-Multilevel Governance of Mass Migration in Europe and beyond." We conducted a total of 40 semi-structured interviews in Istanbul and 12 interviews in Vienna. The central sampling criterion was to include persons who had arrived within the last seven years, whose presence was tied to humanitarian or asylum related provisions, and who had thus experienced some form of legal limbo in their recent past. Both Istanbul and Vienna samples included approximately equal numbers of men and women over 18 years of age. In Istanbul, all except two interviewees had temporary protection status (one had a residence permit and one had no legal papers). In Vienna, seven persons were beneficiaries of asylum, four were asylum seekers and one had received subsidiary protection. Our sample includes variation with regards to the ethnicity and socio-economic background of migrants but can be considered homogenous with regards to religious background (Muslim) and experience of legal limbo. Both cases included Syrian citizens, representing an important group within migratory dynamics from the Middle East during the 2010s. While in Istanbul the majority of our interlocutors came from Syria, one person was Palestinian, and one was Circassian. The Viennese sample included six Syrians, five persons from Afghanistan and one person from Iran.

The difference in the size of samples resulted from the different sizes of the research teams as well as limited resources. While the 40 interviews in Istanbul can be considered at the upper end of qualitative sample sizes, the 12 interviews in Vienna are located at the bottom. Yet, in line with Guest, Bunce, and Johnson (2006), who contend that on the average, 12 interviews of a homogenous group are sufficient to reach a knowledge saturation, we assume the Viennese sample to be within an acceptable scope size-wise. Limitations however arise out of the fact that all Syrians in Vienna were beneficiaries of asylum, while only one Afghan carried a protection title. Likewise, this sample displays a greater variation with regard to socio-economic backgrounds than the Istanbul sample.

The interviews in Istanbul were conducted between July and September 2018 and in Vienna between August 2018 and January 2019. The recruiting process of interlocutors in both cities benefitted from existing con- tacts among civil society actors and NGO members active in the field of refugee reception and integration. In Istanbul, the assistance of an Arabic-speaking research assistant was also essential for securing migrants' participation. We established our first contacts via these gatekeepers and later combined this approach with snowballing. Typically, interview situations were preceded by written conversations, or small talk often including intermediary persons. These aspects contributed to establishing a trusting relationship and thus added to the validity of data.

The interview guide covered: (1) general questions about the person, (2) their current everyday life in Turkey/Austria, including questions of housing, employment and educational activities, (3) their life in the country of origin, (4) the migration journey, (5) their asylum procedure and status, and (6) their current mental and physical health conditions. The conversations varied in length between approximately one to one and a half hours. All participants were provided oral and written information about the aim of the study, confidentiality and voluntary participation. The conversations were recorded, anonymized and transcribed.

In Istanbul, interviews were conducted in Arabic with a native Arabic-speaking research assistant and an author of this study. Interviews were later transcribed and translated into English. In Vienna, most interviews were led in German by the researchers themselves, due the fact that the participants' language skills were sufficient to make sense of our questions and provide meaningful answers. In one instance, the interview was led by a native speaker of Dari, who had received a thorough introduction by the project leader on methodical and ethical approaches. In many German language interviews however, we had to deal with grammatical errors during the transcription. In order to render the material accessible to researchers other than those involved in the interviews, we changed the grammatical structure of sentences where necessary and only to the degree that it did not alter the meaning of a statement. In case of doubt about the meaning, we refrained from editing.

Once the conversations were transcribed, we conducted a software-supported content analysis of the interview material. This method allows for a systematic analysis of verbal communication and is apt for a contextualized reconstruction of personal perceptions (Krippendorf, 2004). First, we looked at the manifest, descriptive dimension of the material, relating to condensed meaning units that we captured in specific codes. We combined this approach with a hermeneutic exploration of the latent, interpretive dimension of the material by reading and analysing longer text passages, which include latent patterns representative of four dimensions of belonging. Namely, we examined belonging in terms of identification and feelings of attachment characterized as "naturalness," "safety," "home" and "comfort." This deductive approach was apt as the categories have already been deployed in existing empirical research 
(Simonsen, 2017, p. 22), offering both teams a standardized template for analysis. Four dichotomies were thus used in order to capture perceptions of belonging or nonbelonging: naturalness-distinctiveness, safety-threat, home-alienation, and comfort-discomfort. In order to examine the role of opportunity structures and public political discourses, latent patterns thereof were traced in relation to discussions of:

- Social encounters: e.g., "when I met them..." "people here..." "Austrians/Turks are..."

- (Non-)participation in institutional or organizational settings: e.g., problems and chances regarding the labour market, language courses, education, and social benefits. Here, we paid particular attention to elements that are specifically related to interviewees' circumstances of living in the two cities.

- Public political discourse: e.g., "the media reports that..." "they think we are..." "politicians say that..."

\section{Findings: Striving towards a Tenuous Normalness within Cities and amidst Religious Debates}

Among our interlocutors in both cities, the topic of being in legal limbo was unsurprisingly a highly relevant issue. It was discussed in a variety of contexts and typically carried attributions of fear and uncertainty. Two reoccurring themes were the inability to establish solid expectations about the future as well as the feeling of being a partial member of society who cannot decide about his/her own destiny (although the latter appeared to be more pronounced in the case of Vienna). On an emotional level, this oftentimes implied a constant state of worrying or a sense of lethargy.

For example, a 26-year-old female migrant with Temporary Protection Status in Istanbul, related:

I am afraid about tomorrow, not from the far future, but about tomorrow I am afraid. I am living an unknown destiny. You don't know if you will stay here or travel to a European country or go back to Syria. Most of the Syrian people who are living here have an unknown destiny.

Similarly, a 26-year-old male asylum seeker in Vienna, explained:

What is our future here: We cannot decide that ourselves, the others decide about our future. That's bad, if you can't do something for yourself, then there are big problems. But yes, life is like that, like the Austrians say "let' s wait and see."

Thus, what role does the city and public political discourse play in this context?

\subsection{Belonging Mediated through Organizational Boundaries: Opportunity Structures at the City Level}

Against the background of partial exclusion at the national level, our interviewees positively associated both Istanbul and Vienna with classical features of large cities in general: increased labour market opportunities, ethnic networks due to pronounced socio-cultural diversity and anonymity. Particularly in Istanbul, people expressed a sense of local embeddedness, with some explicitly relating their belonging to the city's indirect opportunity structures. This feeling was largely linked to their ability to survive and thrive through finding employment and as a consequence learning the language, meeting people and enjoying their neighbourhood. For instance, a 34-year-old woman with Temporary Protection Status in Istanbul related that she felt happy because she is running her own childcare centre:

When I started working, the situation became better somehow. But still the work situation is not stable. There is no work permit and we have low salaries. This is the only difficult thing. Other than that, the society is so good, and there are a lot of places for children to play, so we are happy here.

There is a clear disconnect between her sense of being integrated and comfortable on the one hand, but also unstable with regard to the lack of legal certainty on the other. Whereas economic conditions in Istanbul render irregular employment a viable, although precarious, option to engage in social and economic life, this is no real alternative within the highly regulated Austrian labour market. Here, the welfare state provides minimum living standards, but strongly restricts and controls labour market participation. What remains for migrants in Vienna are direct opportunity structures. One could hardly assume that asylum seekers are able to relate them to city policies and thus thematise them explicitly as such. However, given the fact that they can make a substantive difference in everyday life, we looked deeper into the ways in which our interviewees thematised activities, which we knew or could assume were provided or supported by the city administration.

Here, we found that minor employment, language courses and vocational basic education courses may be the only meaningful structure in the everyday lives of asylum seekers, which is otherwise characterized by endless waiting, sleeping or watching internet videos. These activities are often the first articulated in response to what one currently does in his/her everyday life-simply because there are barely any other occupations constituting some kind of social life. The normalness and naturalness expressed in relation to these activities is only made possible through inclusionary city level policies, which, on a daily basis, compensate for an otherwise lonesome life in reception facilities. Educational courses and minor formal work opportunities were often ad- 
dressed as venues for establishing networks, gathering systemic knowledge about "how things work in Austria," or simply being busy. Thus, they display an intrinsic social value.

However, what appears to be equally important is the instrumental character of these activities. They do not only offer moments of comfort or safety but are also experienced as efforts towards what is perceived as necessary for integrating and what is oftentimes attached to hopes of improving one's prospect of stay. In some instances, interlocutors described the discrepancy between their efforts to integrate on the hand and immigration authorities' reluctance to recognize these efforts when making decisions on their status on the other hand. Thus, city-level opportunity structures, while creating a sense of normality among persons in a legal limbo, also reinforced awareness of a growing dilemma between their individual efforts to become part of society and the national policy logics of granting statuses:

Integration is a little bit like...I got a negative decision for my asylum application. In the first interview, I had 15 letters of recommendation from other people. "Yes, we know this person. He is a good person and we hope that he can stay here." But with the BFA [Immigration Office], it didn't matter at all. Integration, ok, voluntary work, I already learned the language, I got to know so many people in Austria. Or school and so on....But if all these things are not integration, what does integration mean? (Male asylum seeker, 18 years old)

In the case of Istanbul, target group specific integration structures at the city level played a minor role. Clearly, a reason for this might be the lack of systematic offerings throughout the city and the fact that meaningful services are provided by many different groups. Integration-related activities are only sometimes associated with municipalities. Furthermore, there is no immediate prospect of receiving a different status, similar to beneficiaries of asylum in Austria. As a consequence, the perceptions of our interviewees in Istanbul reflect a relatively minor pressure to adopt particular skills (like language ability) or attributes (like cultural practices) to become integrated.

In contrast, we found that explicit perceptions of the city as an imagined urban community of relevance to our interlocutor's situation were more pronounced in Istanbul than in Vienna. This relates to perceptions of the city or to Viennese/Istanbul people as different from Austria/Turkey and Austrian/Turkish people. Although not a dominant aspect, some interviewees experienced Istanbul as an Islamic and Ottoman cultural centre within Turkey. They were familiar with it even before the war through tourist advertisements and Turkish television shows based in Istanbul. One 40-year-old woman with Temporary Protection Status explained:
In the past when I was in Aleppo and walking between the shops, I always saw many tourist shops with a lot of advertisements about Istanbul, saying that Istanbul is heaven on earth. I was always thinking: "When can I go there?" And saying to myself "Allah is Generous, maybe one day I will go there." So I decided to go to Istanbul. But I didn't think that I would come as a refugee.

In Vienna, there were no explicit notions of attachment to the specific urban locality deriving from established ideas of what the city stands for in relation to immigrant opportunities and in opposition to the national level.

\subsection{Belonging Mediated through Conceptual Boundaries: Discourses on Integration and Culture}

In both cases, our interlocutors were strikingly affirmative of dominant national public political discourses on culture and integration. In Istanbul, this means that our interviewees explicitly addressed historical culturalreligious ties, whereas in Vienna this involved implicit compliance with dominant discourses by deemphasizing Muslim identity and addressing claims of individual efforts to integrate within a meritocratic system. Across all interviews, cultural debates were mainly perceived as debates on religion and ethnicity. In Istanbul, such debates were largely a mediator of comfort and naturalness; in Austria, they were a source of discomfort and alienation.

As discussed, dominant political discourses in Turkey posit a cultural and religious connection between Turks and Syrians. Some of our interviewees claimed to feel at home in Turkey's religious milieu and due to a shared Ottoman past. For example, a 52-year old man with Temporary Protection Status related:

We chose Istanbul because it is the biggest city which has Islamic rituals. It was the capital city of Islamic countries, so it still has an Islamic spiritual side, and it is part of our spiritual identity....Because it was ruled by the Ottomans, it gives you an Islamic and oriental spirit more than other cities.

He went on to praise Turkish president Erdoğan, who he argued "is working on our behalf." He compared President Erdoğan to an historical Muslim military leader, Salah Al Din, who unified Syria, Egypt and Mesopotamia.

In contrast to such statements, interviewees in Vienna expressed a sense of alienation, given the fact that the category of "Muslim" is often politically used as a marker of difference and even more of deviance. This perceived symbolic rejection from national level politics is reflected in an asylum seeker's discussion of the meaning of integration:

The Islamic people, if they give away their Islamic religion, then they are well integrated. If they give nothing away, then they are not well integrated. Why is 
that so? Because the politicians and so on, they want to take away the religion of [people from] Islamic countries and so on, and then they say: "You can just integrate." (Male asylum seeker, 26 years old)

Such a position however did not necessarily imply an affirmation of one's own religious identity. In fact, throughout our interviews, statements on religion were often followed by comments relativizing its role in our interlocutor's lives. This became particularly evident during the introduction part of the interview, where the question of one's religion was only one of many short-answer bullet points, but interlocutors frequently further elaborated, as in this example:

Religion, I don't know, my mother and father are Muslims, but I can't necessarily say I'm a Muslim....So I don't know, religion is not so important for me. (Female beneficiary of asylum, 31 years old)

This is also interesting against the background of some interviewees' statements about their appreciation of a liberal society and the freedom from intrusive religious rules that they experience.

Rather, Viennese interviewees expressed anger about national authorities who seemingly cared more about what one is in terms of his/her religion than about what one is doing in terms of integration efforts. They perceived politicians as promoters of a negative discourse on migrants, arguably creating stereotypes and setting them in a criminal context. In some instances, this was contrasted with real life encounters with people "on the street" who were argued to be different, namely welcoming. In other instances, our interlocutors described how a negative discourse was mediatized and adopted by "normal" people. They would thus receive weird looks on the street or experience racism.

In the case of Istanbul, we also found statements both contrasting with and also affirming national level political discourses with social encounters. Some interlocutors juxtaposed the acceptance they felt from the president and other political leaders to the rejection they experienced among some Turkish neighbours who they think have gotten inaccurate and negative information about Syrians from news sources. A 46-year-old woman with Temporary Protection Status explained:

There are some conditions where the Turkish people are not good, but it is normal, generally they are good....They have the right to be afraid of us. They hear the news and feel afraid of us. They are good in general thanks to President Erdoğan. My only dream is to meet him.

Interviewees in Istanbul often asserted belonging by latching onto the public political discourse of shared history and religiosity, which some specifically linked to President Erdoğan's influence, and they contrasted this with negative media reports that they felt are increasing tensions with neighbours. Although people described some religious discrimination, for example due to their style of wearing a headscarf, many interlocutors claimed to have positive interactions due to their being Muslim. A common example given is that migrants are appreciated by neighbours for being able to recite the Qur'an with correct pronunciation. Thus, amidst some discrimination and negative treatment from neighbours, the public political discourse on religion and neighbours' appreciation for their religiosity fosters a tenuous sense of belonging.

\section{Conclusion}

This article explored experiences of (non-)belonging among forced migrants in a similar legal limbo, addressing the role of cities and public political discourses. The two cities we study, it seems, are able to create a minor sense of belonging, which is mainly articulated in terms of social normalness within a period of life otherwise considered anomalous or exceptional. However, this sense of belonging is at best implicitly felt on a day-to-day basis and cannot compensate for the long-term fear and lethargy produced by legal limbo. In Vienna, the capital of a classical destination country, where forced migrants have a chance of receiving a stable legal status as beneficiaries of international protection, city level opportunity structures are perceived as a basis for personal efforts of putting down roots and thus showing that one is integrating. In Istanbul, which may be both a transit or destination city, indirect opportunity structures and the imagination of the city's historical and cultural qualities are the key features conferring belonging.

However, our research also shows that these mediators of belonging remain inevitably tied to a person's legal status. Statuses attributed from the state level are the core point of reference when it comes to both people's practical life planning, but also to their engagement in opportunity structures at the city level. Discussions of engagement in both socio-economic opportunity structures and politically created target group specific integration structures are deeply related to notions of what one cannot do given his/her status or what one could potentially do with a stable status. The case of Vienna demonstrates how integration opportunities are sometimes seized upon in an instrumental manner. This leads to a growing dilemma for individuals who fully comply with a dominant national integration paradigm, but whose longstanding efforts remain disregarded by national immigration authorities.

The importance of the second dimension, namely national political discourses on integration and culture cannot be overlooked. The cases selected offered the opportunity to compare experiences of belonging among forced migrants with Muslim background in two different national settings with differing political discourses: one underscoring the shared cultural heritage of Islam, 
the other highly sceptical of Islam. In both cases, forced migrants engage in discourses similar to those dominant in the public sphere: in Istanbul about their similarity to Turks' religion and culture and in Vienna about the importance of individual integration efforts to become more "Austrian." Clearly, this article cannot provide a quantitative account of the determinates according to which more or less religious migrants chose one place of destination over another. Considering pre-existing ideas about the city of Istanbul, it is of course possible that some migrants to Turkey have positive associations with the notion of living in a pre-dominantly Muslim society before migration. Likewise, such findings have to be considered against the background of a social desirability bias inherent to qualitative research. Yet, regardless of whether religious identity is affirmed or downplayed, it is striking to see the sensibility of interlocutors in both Vienna and Istanbul concerning the role of Islam for public notions of "us" and "them." In the case of Austria, perceptions typically appeared to be racialized in content, just as literature suggest, yet they could also be seen as an independent marker of difference. In Istanbul, the framing of Syrians as "religious brothers" forms a basis for superseding the perception of ethnic differences between Turks and Arabs.

Our research shows that legal limbo remains a serious issue as this topic was repeatedly raised by interviewees who feel frustrated, sad and indeed, often hopeless as a result of it. This article has tried to offer new perspectives on the role of cities and national discourses for fostering identification and attachment. We argue that understanding belonging requires a differentiated picture. Future research must further examine the role of such soft mediators of belonging, without romanticizing them nor overlooking long-term issues in relation to legal limbo.

\section{Acknowledgments}

This research was conducted under the EC-funded Horizon 2020 project "RESPOND-Multilevel Governance of Mass Migration in Europe and Beyond," grant No. 770564 (https://www.respondmigration.com). We thank the Project Coordinators, Andreas Onver Cetrez (Uppsala University) and Soner Onder Barthoma (Uppsala University) and our fellow project team members in Turkey, Ayhan Kaya (Istanbul Bilgi University), Ela Gokalp Aras (Swedish Research Institute Istanbul) and Zeynep Sahin Mencutek (Swedish Research Institute Istanbul) for their support of our research. We also extend our sincere gratitude to all of the migrants who shared their thoughts with us as part of this project.

\section{Conflict of Interests}

The authors declare no conflict of interests.

\section{References}

Ager, A., \& Strang, A. (2008). Understanding integration: A conceptual framework. Journal of Refugee Studies, 21(2), 166-191.

AIDA. (2018). Country report: Turkey. Asylum Information Database. Retrieved from https://www. asylumineurope.org/reports/country/turkey

Anderson, B. (1991). Imagined communities: Reflections on the origin and spread of nationalism. London: Verso.

Antonsich, M. (2010). Searching for belonging-An analytical framework. Geography Compass, 4(6), 644-659. https://doi.org/10.1111/j.1749-8198. 2009.00317.x

Atac, I., \& Rosenberger, S. (2013). Inklusion/ExklusionEin relationales Konzept der Migrationsforschung. [Inclusion/exclusion $-A$ relational concept in migration research]. Göttingen: V\&R Press.

Bauder, H., \& Gonzalez, D. A. (2018). Municipal responses to illegality. Urban sanctuary across national contexts. Social Inclusion, 6(1), 124-134.

Callen, Z. (2004). Imagining the city: Urban politics and imagined communities. Paper presented at the Political Theory Conference, Colorado.

Castles, S., de Haas, H., \& Miller, M. J. (2013). The age of migration. London: Palgrave Macmillan.

Cederberg, M. (2013). Public discourses and migrant stories of integration and inequality: Language and power in biographical narratives. Sociology, 48(1), 133-149.

Chambers, S., Evans, D., Messina, A., \& Williamson, A. (Eds.). (2017). The politics of new immigrant destinations: Transatlantic perspectives. Philadelphia, PA: Temple University Press.

Chatty, D. (2010) Dispossession and forced migration in the 21st-century Middle East and North Africa. Bulletin for the Council for British Research in the Levant, 5(1), 39-42.

Chatty, D. (2017). The duty to be generous (karam): Alternatives to rights-based asylum in the Middle East. Journal of the British Academy, 5, 177-199.

Coşkun, G. B., \& Yılmaz Uçar, A. (2018). Local responses to the Syrian refugee movement: The case of district municipalities of Istanbul, Turkey. Movements-Journal for Critical Migration and Border Regime Studies, 4(2), 103-246. Retrieved from https://movements-journal.org/issues/07.opencall/06.coskun, yilmaz-ucar- $\bigvee$-local-responses-tothe-syrian-refugee-movement.html

Crowley, J. (1999). The politics of belonging: Some theoretical considerations. In A. Geddes \& A. Favell (Eds.), The politics of belonging: Migrants and minorities in contemporary Europe (pp. 15-41). Aldershot: Ashgate.

de Graauw, E., \& Vermeulen, F. (2016). Cities and the politics of immigrant integration: A comparison of Berlin, Amsterdam, New York City, and San Francisco. Jour- 
nal of Ethnic and Migration Studies, 42(6), 989-1012.

Directorate General of Migration Management. (2019). Gecici koruma [Temporary protection]. Directorate General of Migration Management. Retrieved from http://www.goc.gov.tr/icerik6/gecicikoruma_363_378_4713_icerik

Efe, I. (2018). A corpus-driven analysis of representations of Syrian asylum seekers in the Turkish press 2011-2016. Discourse \& Communication, 13(1), 1-20.

Erdal, M. B., \& Oeppen, C. (2018). Forced to leave? The discursive and analytical significance of describing migration as forced and voluntary. Journal of Ethnic and Migration Studies, 44(6), 981-998.

Erdoğan, M. (Ed.). (2017). Kopuştan Uyuma Kent Mültecileri. Suriyeli Mülteciler ve Belediyelerin Süreç Yönetimi: Istanbul Örneği [City refugees from rupture to social harmony. Syrian refugees and municipal process management: The example of Istanbul]. Istanbul: Marmara Belediyeleri Birligi Kultur Yayinlar. Retrieved from http://marmara.gov.tr/UserFiles/ Attachments/2017/04/14/dcc6a30e-e9ed-4e99920b-cdfa7544e370.pdf

Foner, N., \& Alba, R. (2008). Immigrant religion in the U.S. and Western Europe: Bridge or barrier to inclusion? The International Migration Review, 42(2), 360-392.

Garcés-Mascareñas, B., \& Penninx, R. (Eds.). (2016). Integration processes and policies in Europe: Contexts, levels and actors. Berlin: Springer.

Geddes, A. (2005). Europe's border relationships and international migration relations. Journal of Common Market Studies, 43(4), 787-806.

Goldring, L., \& Landolt, P. (2011). Caught in the workcitizenship matrix: The lasting effects of precarious legal status on work for Toronto immigrants. Globalizations, 8(3), 325-341.

Gruber, O., Mattes, A., \& Stadlmair, J. (2016). Die meritokratische Neugestaltung der österreichischen Integrationspolitik zwischen Rhetorik und Policy [The meritocratic restructuring of Austrian integration politics between rhetoric and policy]. ÖZP, 45(1), 65-79.

Guest, G., Bunce, A., \& Johnson, L. (2006). How many interviews are enough? An experiment with data saturation and variability. Field Methods, 18(1), 59-82.

Hickman, M., Mai, N., \& Crowley, H. (2012). Migration and social cohesion in the UK. London: Palgrave Macmillan.

Howes, L., \& Hammett, D. (2016). Negotiating identities and emotional belonging: Shan in northern Thailand. Emotion, Space and Society, 19, 21-28. https://doi. org/10.1016/j.emospa.2016.04.001

Kannabiran, K., Vieten, U., \& Yuval-Davis, N. (2006). Introduction to special issue. Boundaries, identities and borders: Exploring the cultural production of belonging. Patterns of Prejudice, 40(3), 189-195.

Kassaye, A., Ashur, I., \& van Heelsum, A. (2016). The relationship between media discourses and belonging: Dutch Somali perspectives. Ethnicities, 16(6), 773-797.
Kaya, A. (2016). Vulnerability assessment of Syrian refugees in Istanbul (April 2016 Report). Istanbul: Support to Life. Retrieved from https://data2.unhcr. org/ar/documents/download/54518

Krippendorf, K. (2004). Content analysis: An introduction to its methodology. London: Sage Publications.

Lambert, N., Stillman, T., Hicks, J., Kamble, S., Baumeister, R., \& Fincham, F. (2013). To belong is to matter: Sense of belonging enhances meaning in life. Personality and Social Psychology Bulletin, 39(11), 1418-1427.

Mattes, A. (2017). Who we are is what we believe? Religion and collective identity in Austrian and German immigrant integration policies. Social Inclusion, 5(1), 93-104.

Morris, L. (2003). Managing contradiction: Civic stratification and migrants' rights. International Migration Review, 37(1), 74-100.

Penninx, R. (2009). Decentralising integration policies: Managing migration in cities, regions and localities. London: Policy Network. Retrieved from https:// www.researchgate.net/publication/254916795

Permoser, J., \& Rosenberger, S. (2012). Integration policy in Austria. In J. Frideres \& J. Biles (Eds.), International perspectives: Integration and inclusion (pp. 39-58). Montreal: McGill-Queen's University Press.

Pierce, J., Siddiki, S., Jones, M., Schumacher, K., Pattison, A., \& Peterson, H. (2014). Social construction and policy design: A review of past applications. Policy Studies Journal, 42(1), 1-29.

Robertson, S., \& Runganaikaloo, A. (2014). Lives in limbo: Migration experiences in Australia's educationmigration nexus. Ethnicities, 14(2), 208-226.

Schiefer, D., \& Noll, J. (2017). The essentials of social cohesion: A literature review. Social Indicators Research, 132(2), 579-603.

Simonsen, K. (2016). How the Host nation's boundary drawing affects immigrants' belonging. Journal of Ethnic and Migration Studies, 42(7), 1153-1176.

Simonsen, K. (2017). Do they belong? Host national boundary drawing and immigrants' identificational integration (Unpublished Doctoral dissertation). Department of Political Science, Aarhus, Aarhus University.

Simonsen, K. (2018). What it means to (not) belong: A case study of how boundary perceptions affect second-generation immigrants' attachments to the nation. Sociological Forum, 33(1), 118-138.

Simonsen, K. (2019). "Us" or "them"? How policies, public opinion, and political rhetoric affect immigrants' sense of belonging. Migration Policy Institute. Retrieved from https://www.migrationpolicy.org/ article/policies-public-opinion-rhetoric-immigrantssense-belonging

Statham, P., \& Tillie, J. (2016). Muslims in their European societies of settlement: A comparative agenda for empirical research on socio-cultural integration across countries and groups. Journal of Ethnic and Migration Studies, 42(2), 177-196. 
TurkStat. (2018). Migration statistics. Turkish Statistical Institute International Migration Statistics. Retrieved from http://www.turkstat.gov.tr/PreTablo. do?alt_id=1067

van Leeuwen, T., \& Wodak, R. (1999). Legitimizing immigration control: A discourse-historical analysis. Discourse Studies, 1(1), 83-118.

Wodak, R. (2015). "Normalisierung nach rechts": Politischer Diskurs im Spannungsfeld von Neoliberalismus, Populismus und kritischer Öffentlichkeit [Political discourse in the area of tension between neoliberalism, populism and critical public]. Linguistik Online, 73(4), 27-44.

\section{About the Authors}

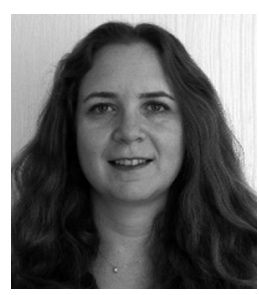

Susan Beth Rottmann obtained her PhD degree in Anthropology from the University of WisconsinMadison in 2012. Currently, she is an Assistant Professor in the Social Sciences Faculty at Özyeğin University in Istanbul, Turkey. Dr. Rottmann studies transnationalism, gender, family and citizenship. In 2019, she published an ethnography of ethics and belonging for German-Turkish return migrants with Berghahn Books, titled, In Pursuit of Belonging: Forging an Ethical Life in European-Turkish Spaces.

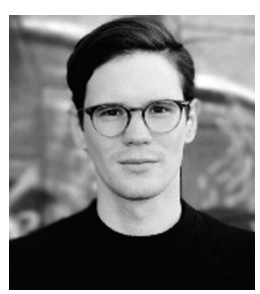

Ivan Josipovic (MA) is Junior Researcher at the Institute for Urban and Regional Research of the Austrian Academy of Sciences. He studied Socioeconomics and graduated in Political Science. His fields of interest comprise border and migration regimes, asylum politics and European integration.

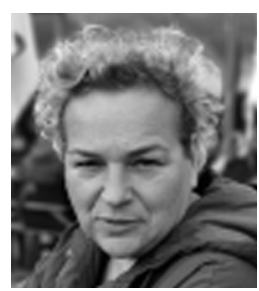

Ursula Reeger (Mag. Dr.) is a Senior Researcher at the Institute for Urban and Regional Research of the Austrian Academy of Sciences, Vienna, Austria; her research interests include international migration and its impacts, integration processes (on the labour and the housing market), interethnic relations on the local level, and governance of migration and migrant integration. 